Article

\title{
Importance of Plants with Extremely Small Populations (PSESPs) in Endemic-Rich Areas, Elements Often Forgotten in Conservation Strategies
}

\author{
Donatella Cogoni $^{1}{ }^{\complement}$, Giuseppe Fenu ${ }^{2, *}$ C, Carlo Dessì ${ }^{3}$, Angela Deidda ${ }^{4}$, Cesario Giotta ${ }^{5}$, Marcello Piccitto ${ }^{6}$ \\ and Gianluigi Bacchetta ${ }^{1}$ (I)
}

1 Centro Conservazione Biodiversità (CCB), Dipartimento di Scienze della Vita e dell'Ambiente, Università degli Studi di Cagliari, Viale Sant'Ignazio da Laconi 13, 09123 Cagliari, Italy; d.cogoni@unica.it (D.C.); bacchet@unica.it (G.B.)

2 Dipartimento di Scienze della Vita e dell'Ambiente, Università degli Studi di Cagliari, Viale Sant'Ignazio da Laconi 13, 09123 Cagliari, Italy

3 Independent Researcher, Vico Sant' Ignazio 22, 09090 Laconi, Italy; carlettodessi60@gmail.com

4 Independent Researcher, Via Frumini 13, 09090 Laconi, Italy; angeladei@tiscali.it

5 Independent Researcher, Viale Marconi 82, 08045 Lanusei, Italy; cesariogiotta@tiscali.it

6 Istituto d'Istruzione Superiore Leonardo da Vinci, Via Leonardo da Vinci1, 08045 Lanusei, Italy; marcellopiccitto@tiscali.it

* Correspondence: gfenu@unica.it

\section{check for} updates

Citation: Cogoni, D.; Fenu, G.; Dessì, C.; Deidda, A.; Giotta, C.; Piccitto, M.; Bacchetta, G. Importance of Plants with Extremely Small Populations (PSESPs) in Endemic-Rich Areas, Elements Often Forgotten in Conservation Strategies. Plants 2021, 10, 1504. https://doi.org/10.3390/ plants10081504

Academic Editors: Emmanuele Farris and Javier López-Alvarado

Received: 9 June 2021

Accepted: 18 July 2021

Published: 22 July 2021

Publisher's Note: MDPI stays neutral with regard to jurisdictional claims in published maps and institutional affiliations.

Copyright: (c) 2021 by the authors. Licensee MDPI, Basel, Switzerland. This article is an open access article distributed under the terms and conditions of the Creative Commons Attribution (CC BY) license (https:/ / creativecommons.org/licenses/by/ $4.0 /)$.

\begin{abstract}
The distribution of the threatened fern Ophioglossum vulgatum L., a plant with extremely small populations (PSESPs) in Sardinia, is characterized by small disjunct populations with only a few individuals, and little is known about its status in the wild. To provide information for the conservation of $O$. vulgatum and with the aim to develop an in situ conservation strategy, we investigated its distribution, population size, and habitat. Field surveys confirmed that the species grows in only five localities. Two representative populations were selected for this study (Funtanamela and Gedili), and in each population, all plants were mapped and monitored monthly from April to August over an 8-year period. During the study, the populations had a very low number of reproductive plants and the populations appeared to be in decline, with the total number of plants per population slightly decreased in Gedili while a sharp reduction was recorded in Funtanamela due to wild boar threat. A fence was built in order to protect the site from further damage, but no noticeable signals of recovery were observed. The most urgent conservation requirement for this species is to preserve the threatened habitat of the remnant populations. Further field surveys and research are also required for an improved understanding of the species' status.
\end{abstract}

Keywords: evolutionary potential loss; knowledge gaps; Mediterranean flora; monitoring activities; Ophioglossum vulgatum L.; plant conservation; Sardinia

\section{Introduction}

Island ecosystems have always played a leading role in conservation biology, and generally are hotspots of biodiversity [1-3], with legacies of relatively recent human impact and native species' extinctions, and therefore provide significant challenges when considering how to conserve biodiversity. They also offer some of the best-suited scenarios for rapidly advancing our understanding of fundamental aspects of human relationships with nature, and of conservation strategies [4].

Despite the high biodiversity value, island plant diversity is severely threatened both by natural and anthropogenic factors, including geological events, plant-animal interactions, stochastic events, species invasions, land-use change, habitat destruction or fragmentation, overharvesting for economic purposes, and global climate change (e.g., [5-11]). Indeed, it is widely recognized that most Earth ecosystem processes are being altered by 
human activities, suggesting that we may have entered a human-dominated geological epoch called the "Anthropocene" [12], and that humans are causing the sixth mass species extinction (e.g., $[13,14])$. These serious threats are the cause of numerous extinctions recognized in insular context worldwide [15-18], and their knowledge can be considered a clarion call to increase global efforts to study, halt, and possibly reverse the ongoing negative environmental trends [14].

Mediterranean islands encompass a wide range of habitats within a small and restricted range; past geographical and climatic changes, combined with current environmental heterogeneities, have molded, within them, unusually high levels of biodiversity, which is very important for their own value of biodiversity, both in term of plant species (i.e., numerous endemics, presence of "climate relicts") and of ecosystems' assemblage $[2,6,19,20]$. As they comprise a variety of valuable habitats, insular ecosystems are considered more fragile than continental ones, while the uncertainty regarding the conservation of valuable native flora is much more exacerbated in insular habitats than in their mainland counterparts [21].

Sardinia, the second largest island in the Mediterranean Basin, is exceptionally rich in plant diversity, with more than 2450 vascular taxa [22]; among them, 295 are endemics (189 exclusive Sardinian endemics, 90 Sardinian-Corsican endemics, and 16 that are also present in the Tuscan Archipelago) as a result of the geographical isolation and a high geological and geomorphological diversity that have contributed to the formation of a wide range of habitats and consequent high rate of endemism (e.g., [3,23]). In such endemic-rich areas, the conservation concerns are so far all focused on the endemic component, since these species are usually better studied and frequently more threatened than the nonendemic flora and constitute a central group for conservation [3,21], since the conservation of biodiversity occurs via the implementation of policy with only limited resources [24-26]. In this context, Sardinia is not an exception: despite the high level of uniqueness in the vascular flora, until a few years ago not many conservation studies and actions had been carried out on threatened plant species, and the few studies were mainly oriented on extremely narrow endemic and endemic plants. Only in the last years has a trend inversion been registered, with an increasing number of papers and conservation actions detected about the threatened flora, indicating that greater attention is being paid to threatened plants and, in general, to the island's plant diversity (e.g., [21,27]). Nonetheless, mainly due to limited human and economic resources (e.g., [24,25]), these conservation achievements are not enough to protect Sardinia's high level of plant diversity, therefore conserving the most threatened wild species in the island is more urgently needed than ever before.

Often, in addition to the main human-related threats, the progress of plant conservation action is also hindered by several additional factors, such as management issues (e.g., lack of conservation awareness from governmental officials and local people), which create barriers to conservation success, because very often the importance of conserving even a single species is ignored if its value is not known [28]. It is therefore essential to create a "priority list" of plants for which protection is needed through "regional responsibility" criteria to identify the target species which enrich the levels of biodiversity of a territory [21,29-32]. Unfortunately, as in several Mediterranean areas, in Sardinia there are regional gaps in related laws and regulations regarding wild plant conservation. Furthermore, these lists must be open and include not only endemic species but also other plants of conservation interest, as suggested for the Mediterranean insular floras [21], and, when possible, be capable of highlighting the conservation needs by single population rather than by species [33].

As current conservation efforts of governments, scientists, conservationists, and the general public are often focused on endemic, threatened, and endangered plants, one of the main difficulties is understanding, beyond these species, which wild species should receive protection priority as they favor the values of biodiversity. Among these, wild plants with extremely small populations (PSESPs) deserve conservation interest and have a critical role for sustainable development and for saving biodiversity $[28,34,35]$. To focus on plants 
with extremely small populations with in situ and ex situ conservation action is another fundamental pillar to preserve the level of plant diversity of a region $[28,34,35]$. The PSESP concept refers to species with low numbers and with much lower than minimum viable populations for long-term survival in the wild, due to serious human disturbance in recent times; it excludes naturally rare species. Small remaining populations, restricted habitat, serious human disturbance, and extremely high risk of extinction are key characteristics of PSESPs [28]. Therefore, it is important to study and conserve plant species with small populations, although their distributions are over large territories, not only for their contribution to increase the floristic richness of a territory, but especially for their evolutionary potential [19].

An iconic case of such type of plants is represented by the small fern Ophioglossum vulgatum L. (Ophioglossaceae), widely distributed in the temperate regions of the Northern Hemisphere but present only in a few disjunct localities in Sardinia, always in extremely small populations in size. For this fern that has a wide distribution, conservation has not been a priority so far, and very little is known about its ecology and distribution, as well as the population size and dynamic in Sardinia, and even less about its conservation status. In addition to the lack of this information, for Sardinian populations the problems related to its conservation are both the lack of legal regulation that dictate the need for conserving species, and protocols/methodologies for conserving peculiar species that are inadequate and usually do not specify how conservation should take place. In the frame of conservation activities carried out in Sardinia for the endangered flora, and considering the lack of ecological and distributive studies, an extensive monitoring plan for this species started in 2011 with the main aim to develop an in situ conservation strategy. Specifically, this study aimed to provide detailed information about the current status of two selected small populations of this wild plant in Sardinia, subjected to several threats and, consequently, whose conservation is a priority at the regional level. Further aims were to analyze the need for its protection and recommend appropriate conservation measures, therefore we estimated the species' distribution and the single population size, characterized its habitat, and monitored all populations over time.

\section{Results}

As a result of our study, and considering both historical and newly discovered populations, O. vulgatum was recorded (and confirmed) in five Sardinian localities; in particular, three of them reported in bibliography for Funtanamela [36], Riu Monte Cresia and Sa Castangedda [37], and two for which old herbarium specimens had been preserved in Herbarium FI (Gedili; Piccitto and Giotta, 28.VI.1995) or CAG (Riu Giuanni 'e Cannas; Lai, 15.V.1998; Table 1 and Figure 1). An old herbarium specimen of O. vulgatum, collected in 1967 and stored at the Herbarium CAG, comes from a coastal brackish pond located in the northwest of the island, near Stintino (Table 1).

In Sardinia, Ophioglossum vulgatum currently grows on various lithological substrata (carbonate and intrusive), where a pedogenetically evolved humus-rich soil horizon was present, in flat areas at altitudes ranging from 630 to $760 \mathrm{~m}$ a.s.l. (Table 1). In the island, this species usually occurs in humid meadows habitats, often under riparian formations characterized by peculiar species such as Taxus baccata L. and Cornus sanguinea L. All populations of Ophioglossum vulgatum grow in areas that can be referred to as the Mediterranean euoceanic bioclimate and, more specifically, a lower meso-Mediterranean thermotype and lower subhumid ombrotype.

All populations of this rare fern are characterized by a low number of reproductive plants which, on average, varies between 25 and 150 individuals, depending on the years. No population contained $>250$ mature individuals, with a general decreasing trend over the study period (Table 1). 


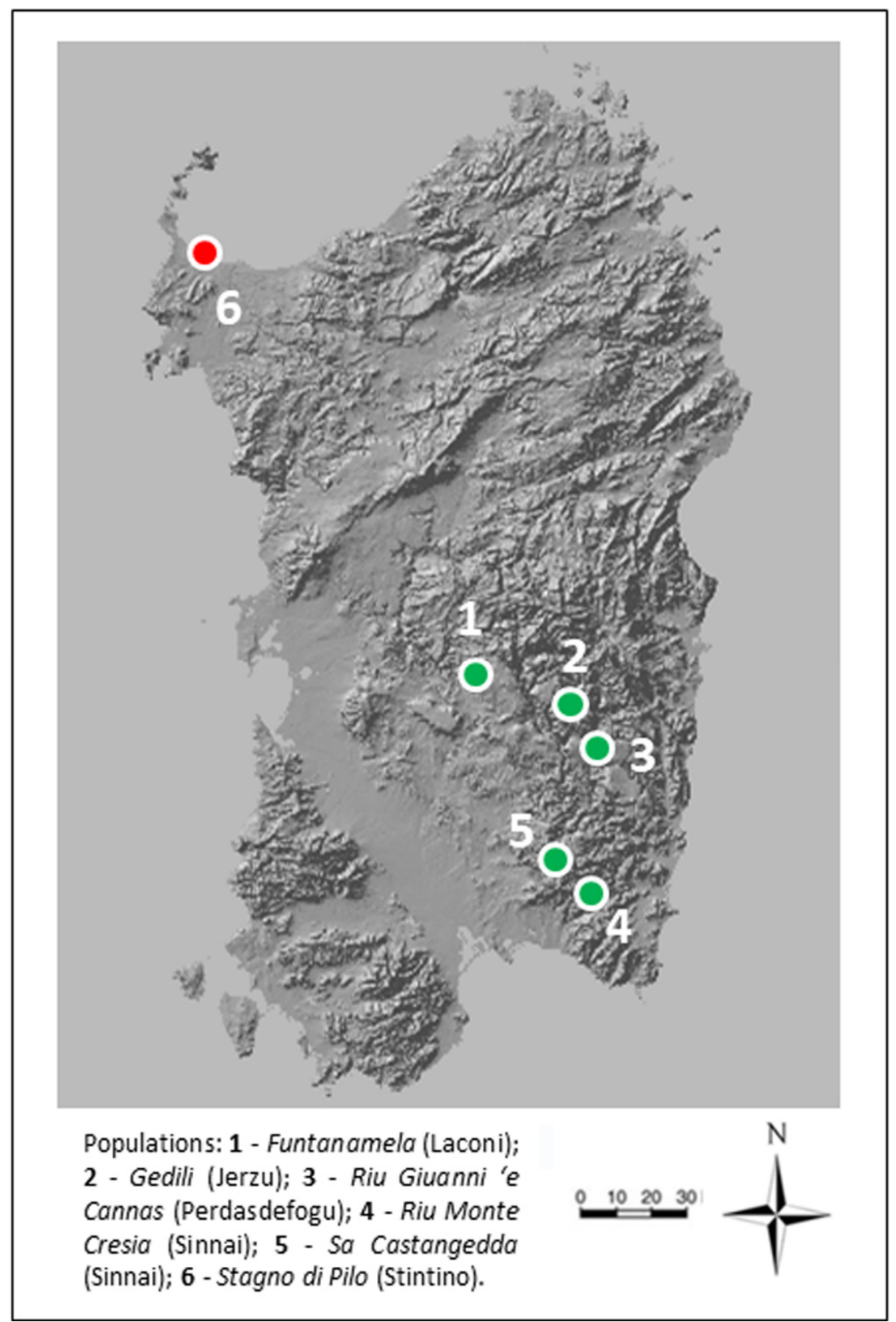

Figure 1. Current distribution of Ophioglossum vulgatum L. in Sardinia: confirmed populations are in green and (probably) extirpated in red.

Table 1. Current situation in term of distribution and ecology of O. vulgatum in Sardinia with mean altitude, slope, aspect, lithological substrata, habitat, land management, first reporting, and current status of each locality where the species grows.

\begin{tabular}{cccccccc}
\hline $\begin{array}{c}\text { Locality } \\
\text { (Municipality) }\end{array}$ & $\begin{array}{c}\text { Mean Altitude } \\
(\mathbf{m} \text { a.s.1.) }\end{array}$ & Substrate & Habitat & $\begin{array}{c}\text { Area } \\
\mathbf{( m}^{\mathbf{2}}\end{array}$ & $\begin{array}{c}\text { Land } \\
\text { Management }\end{array}$ & $\begin{array}{c}\text { First } \\
\text { Reporting }\end{array}$ & $\begin{array}{c}\text { Current } \\
\text { Status }\end{array}$ \\
\hline $\begin{array}{c}\text { Funtanamela } \\
\text { (Laconi) }\end{array}$ & 726 & Travertine & $\begin{array}{c}\text { Riparian } \\
\text { woods }\end{array}$ & 10 & Public & {$[36]$} & Confirmed \\
Gedili (Jerzu) & 760 & Limestone & $\begin{array}{c}\text { Wet } \\
\text { meadows }\end{array}$ & 25 & Private & $\begin{array}{c}\text { M. Piccitto } \\
\text { and C. Giotta } \\
(1995)\end{array}$ \\
\hline
\end{tabular}


Table 1. Cont.

\begin{tabular}{|c|c|c|c|c|c|c|c|}
\hline $\begin{array}{c}\text { Locality } \\
\text { (Municipality) }\end{array}$ & $\begin{array}{l}\text { Mean Altitude } \\
\text { (m a.s.l.) }\end{array}$ & Substrate & Habitat & $\begin{array}{l}\text { Area } \\
\left(\mathrm{m}^{2}\right)\end{array}$ & $\begin{array}{c}\text { Land } \\
\text { Management }\end{array}$ & $\begin{array}{c}\text { First } \\
\text { Reporting }\end{array}$ & $\begin{array}{l}\text { Current } \\
\text { Status }\end{array}$ \\
\hline $\begin{array}{l}\text { Riu Giuanni ‘e } \\
\text { Cannas } \\
\text { (Perdasdefogu) }\end{array}$ & 630 & Limestone & $\begin{array}{l}\text { Wet } \\
\text { meadows }\end{array}$ & 400 & Public & R. Lai (2006) & Confirmed \\
\hline $\begin{array}{l}\text { Riu Monte Cresia } \\
\text { (Sinnai) }\end{array}$ & 660 & Granite & $\begin{array}{l}\text { Riparian } \\
\text { woods }\end{array}$ & 250 & Public & [37] & Confirmed \\
\hline $\begin{array}{l}\text { Sa Castangedda } \\
\text { (Sinnai) }\end{array}$ & 690 & Granite & $\begin{array}{l}\text { Riparian } \\
\text { woods }\end{array}$ & 300 & Public & [37] & Confirmed \\
\hline $\begin{array}{l}\text { Stagno di Pilo } \\
\text { (Stintino) * }\end{array}$ & 5 & $\begin{array}{l}\text { Alluvial } \\
\text { deposits }\end{array}$ & $\begin{array}{l}\text { Brackish } \\
\text { pond }\end{array}$ & $\mathrm{N} / \mathrm{A}$ & $\mathrm{N} / \mathrm{A}$ & $\begin{array}{l}\text { M. Chiappini } \\
\text { (1967) }\end{array}$ & $\begin{array}{c}\text { Not } \\
\text { confirmed }\end{array}$ \\
\hline
\end{tabular}

${ }^{*}$ Herbarium specimen, collected by Chiappini (1967) and stored at Herbarium CAG (University of Cagliari, Italy), that has not been refound in the last 50 years.

The detailed monitoring showed that the vegetative season started in early March for both populations, but the maximum number of individuals per population was observed in May (Funtanamela) or July (Gedili); the population structure showed a dominance of juvenile plants in Funtanamela and mature individuals in Gedili (Figure 2).

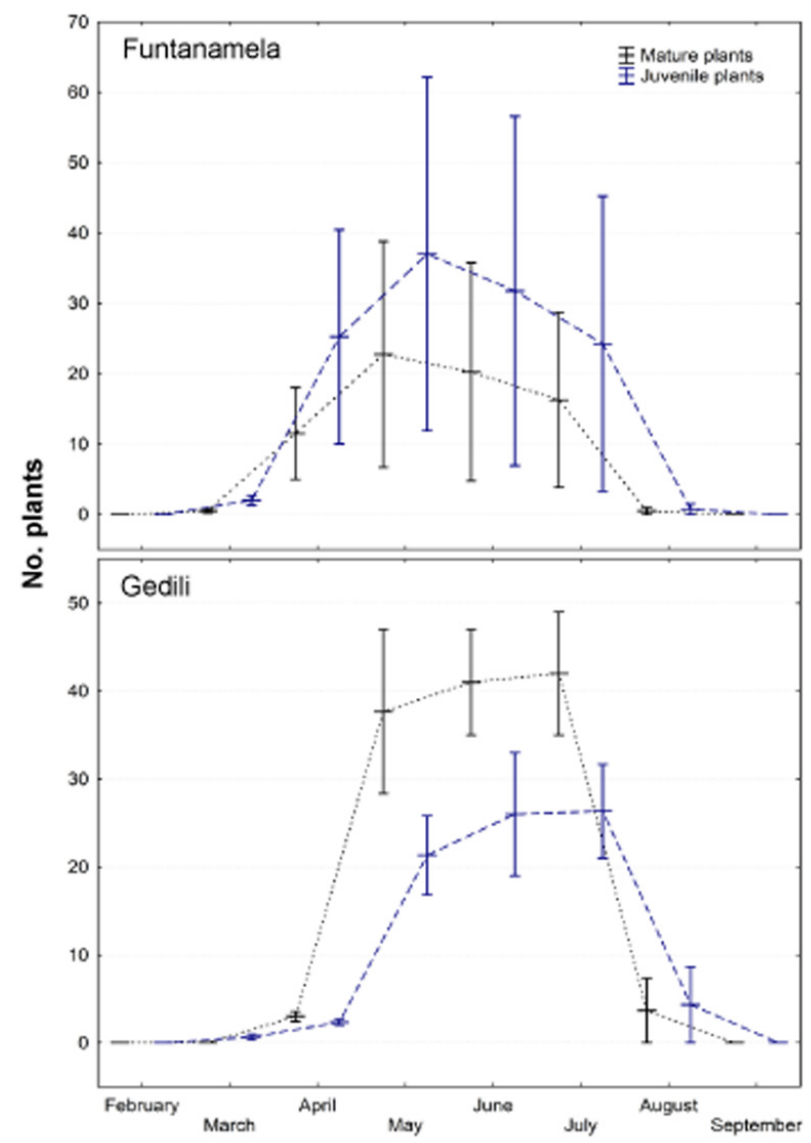

Figure 2. Mean values $( \pm \mathrm{SE}$ ) of juvenile and mature plants per month in Funtanamela (Laconi) and Gedili (Jerzu) during the 8-year period of monitoring.

In 2011, the initial number of monitored individuals varied from 177 to 49 plants in Funtanamela and Gedili, respectively. In winter 2013, before the growing season began, the site where O. vulgatum population grow in Funtanamela had been severely damaged by the rooting activity of wild boars, with a consequent drastic reduction in population size in the following spring (Figure 3). Despite this situation, the University of Cagliari continued the periodic monitoring of both populations. In 2016, in the frame of the Care-Mediflora 
project (http: / / www.CARE-MEDIFLORA.eu/, accessed on 9 June 2021), a fence was built in order to protect the site from further damage by wild boars and to observe whether the O. vulgatum population was able to recover itself naturally (Figures 3 and 4). During the study period, the total number of plants per population slightly decreased in Gedili, while a sharp reduction was recorded in Funtanamela following the event mentioned above. As a consequence of the damage, in this population, $<10$ individuals were always observed both before and after the fence erection; in addition, the number of reproductive plants never exceeded two units, being zero in 2014, 2016, and 2017. During the last monitoring in Funtanamela (2019), six years after the population extirpation and four years after the fence construction, no noticeable signals of recovery were observed.

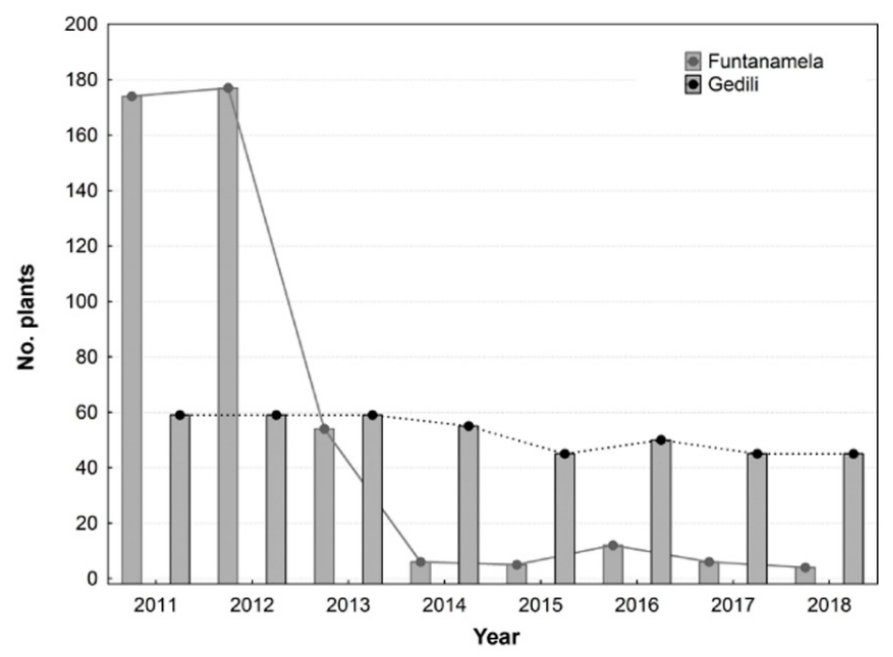

Figure 3. Population size per year in Funtanamela (Laconi) and Gedili (Jerzu) during the 8-year period of monitoring.
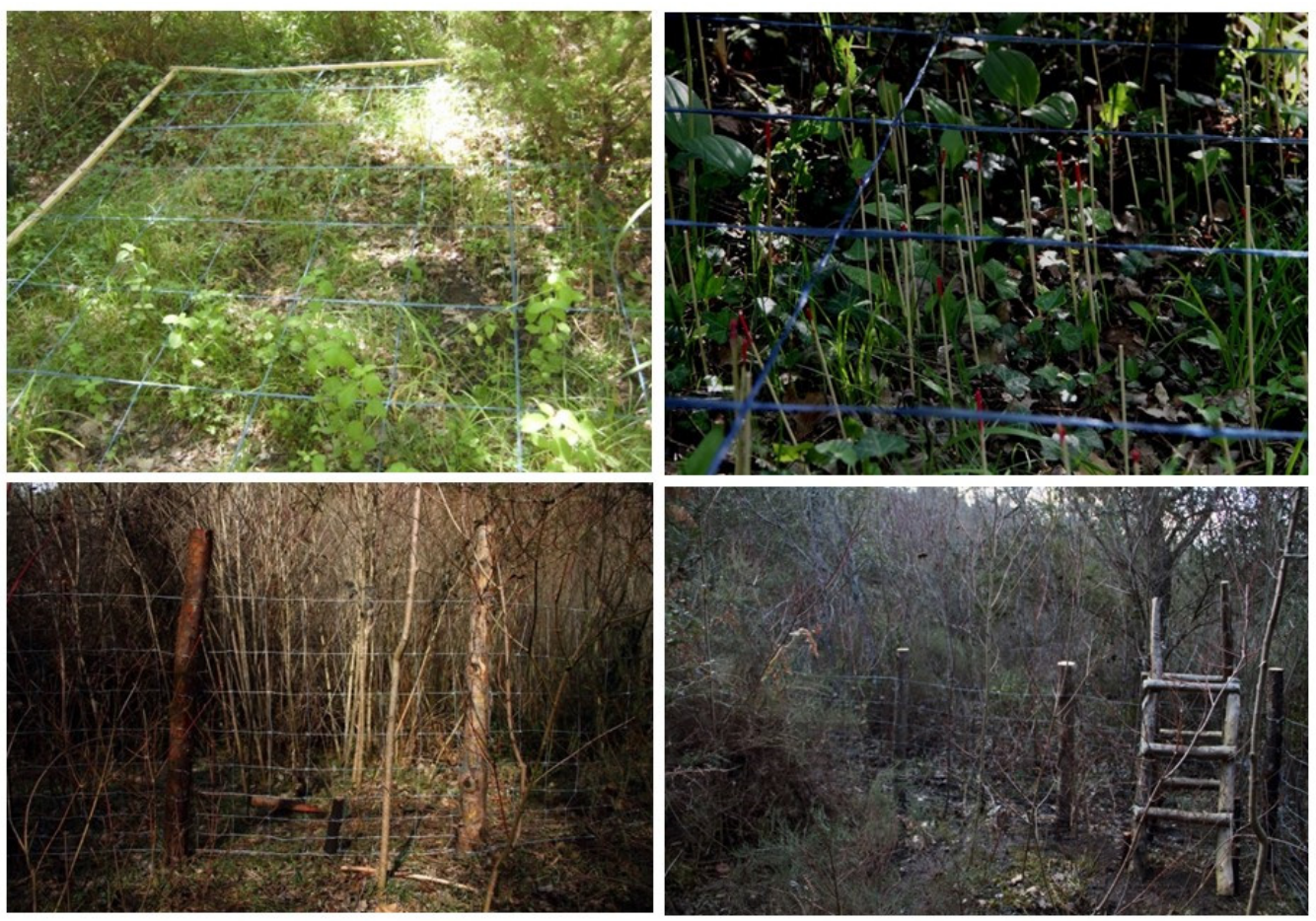

Figure 4. Monitoring protocol using a fixed grid to map each individual plant and different woody stock to distinguish juvenile and mature plants (up); fence protection for the population of Ophioglossum vulgatum at Funtanamela, Laconi (Photo by Giuseppe Fenu and Carlo Dessì). 


\section{Discussion}

Key characteristics of PSESPs are the small remaining populations, often restricted habitat, serious natural and/or human disturbance, and extremely high risk of extinction [28]; therefore, it is important to study and conserve plant species with a small population, although their distribution is over large territories, not only for of their contribution to increase the floristic richness of a territory, but especially for their evolutionary potential [19]. O. vulgatum in Sardinia showed all the typical traits of a PSESP in terms of small and isolated populations, peculiar ecological requirements, high rate of natu$\mathrm{ral} /$ human disturbance, and a probable case of local extirpation associated with a lack of attention to conservation. Our long-term study allowed us, first of all, to obtain a current distribution of this species on the island and detailed ecological and population data. It was interesting to observe how the population structures were different in the two monitored sites with a typical structure of an expanding population in Funtanamela (high number of juvenile plants), against a more stable population in Gedili (high number of mature plants). Although further analyses are necessary, these differences could be due to local ecological situations that become decisive in determining population dynamics, as often happens for small populations (e.g., [38,39]). A separate discussion must be had for the population in the Stagno di Pilo, for which there are no recent confirmations: the herbarium specimen is correctly determined, and the collector was certainly an expert botanist; in addition, it has also been demonstrated that $O$. vulgatum can grow on sandy habitats and tolerate increased $\mathrm{NaCl}$ content in the soil. For these reasons, it is conceivable that this population is extinct due to anthropogenic activities or to some stochastic event such as that observed in Funtanamela.

Some clues for conservationists can be obtained from our long-term monitoring activity. First of all, natural stochastic events can lead to a strong reduction of a plant population or a local extinction; this is particularly relevant when these events occur to the detriment of plants with extremely small populations, such as O. vulgatum in Sardinia. These events, often negligible in space and time, can therefore lead to a loss of biological diversity in a territory, often without the awareness on the part of conservationists. In this context, a peculiar role is linked to the high abundance of ungulates [40-43]; the wild boar (Sus scrofa) activity that affects several taxa both directly and indirectly (e.g., through predation and/or alteration of different ecosystem parameters) is the rooting activity, as this may alter soil and vegetation and overturn extensive areas [40-42]. In fact, this species is considered one of the most invasive species in terms of impact on biological diversity, especially because the population size has increased rapidly in recent decades in several regions of the world [41-44]. To our knowledge, the effects of rooting activity on narrow endemic plants and/or plants with extremely small populations are poorly documented in literature; in our study case, the rooting activity seems to result in a local extirpation of a small population, since no significant recovery of the population has been observed, despite the protections.

Practical conservation actions, such as protective fence erection, may be useless in saving a compromised situation, or can take many years to show their effectiveness. The implementation of passive protection measures represents an emergency solution to limit overgrazing, but comprehensive measures, such as herbivore control (both wild and domestic) accompanied by species-specific translocation, are always preferable [45]. More in general, the use of protective fences to protect threatened populations is a topic currently highly debated among conservationists, and there is no unanimous consensus on the real effectiveness of these measures [45]. As mentioned above, actions can take many years to show their effectiveness. In this specific case, it takes a long time and a lot of constancy in monitoring activities to understand whether the passive defense measures undertaken can be successful on a small population. Therefore, conservation programs should be designed with viable, long-term measures in mind. In addition to the long-term monitoring, at the same time, the evaluation methods for enhancing protection effectiveness are essential to ensure the effectiveness of the conservation measures. 
The few remaining populations of $O$. vulgatum require urgent conservation action, both to protect and reinforce extant populations and, if possible, to reintroduce new populations into suitable sites. To do this, although there are no specific protocols, the experiences gained in recent years on other small ferns could be exploited (e.g., [46,47]).

A further indication is that populations growing on land managed by public administrations are not always more protected, per se, than those growing on private land; it is unanimously accepted that carrying out in situ conservation actions on public land is easier (e.g., $[45,48]$ ), but it is now necessary to also address the issue with the owners of the land where threatened plant populations grow: this is certainly a great challenge for the future that can only be won by involving people and implementing awareness on the challenge of biodiversity conservation.

Unfortunately, although PSESPs have received much attention, especially in China [28,34,49-52], conservation of endangered plants with extremely small populations is particularly difficult, especially because there are few successful examples to follow (e.g., $[44,45])$, and because most wild plant species with extremely small populations are not legally included in official protection programs [34]. In addition, so far no detailed and appropriate protocols/methodologies for conserving PSESPs are available in literature [53]. All these aspects considered, the establishment of small-scale reserves or plant micro-reserves must be recognized as the most appropriate precautionary approach for in situ conservation of PSESPs; against this background, continuous long-term monitoring is essential for successful in situ conservation management of PSESPs (e.g., [53,54]).

Our study demonstrates that the conservation status of a plant globally considered not threatened could notably vary at a small spatial scale; accordingly, such evidence leads us to confirm that conservation priorities should vary at the small local level, since a population could need different conservation measures depending on the particular local conditions [21,33]. Because these species are generally not included in specific regional conservation strategies, most plant species with extremely small populations remain in danger of extinction; a first step at the local level in this direction is the inclusion of these plant species in the regional priority lists (according to the "regional responsibility" criterion) and in the National Red Lists.

In the inexorable homogenization of global biodiversity, plant diversity loss is manifested most obviously and most consistently by the disappearance of rare species such as PSEPs; against this background, conservation action must have a focus on the long-term future of these species to save them wherever and whenever possible in the wild [54]. Ensuring a secure long-term future for plants such as O. vulgatum in Sardinia has important intrinsic value since they encapsulate millions of years of evolutionary history.

\section{Materials and Methods}

Ophioglossum vulgatum L. (Figure 5) is a terrestrial, homosporous, perennial geophyte, 5-30 cm tall, with a single sterile leaf. The spike consists of a variable number, between 10 and 40, of segments on each side [55,56]. The rhizome is usually short and erect, bearing one, rarely two, fronds. The frond is simple, entire, and ovate, 2-5 × 3-12 cm, with an adaxially placed fertile spike, showing $15-50$ sporangia on each side $[55,56]$. Ophioglossum vulgatum is a small fern, the sporophyll sprouts out in April-June and wind is its main spore dispersal agent. This cosmopolitan plant species occurs throughout its range in such diverse habitats as fens, damp sands, pastures, wet meadows, grassy swales, moist woods, rich swamplands, and mud creeks; occasionally it occurs on rocky hillsides or on dry, sandy beaches where it tolerates increased $\mathrm{NaCl}$ content in the soil (e.g., [56,57]). In Europe, Ophioglossum vulgatum usually grows in a variety of wet and mesic habitats, including wet and peaty meadows, marshes, stream edges, and hygrophilous woodlands from sea level up to $1800 \mathrm{~m}$ [56,57]; it is generally considered as a characteristic species of the wet and oligotrophic Molinion caeruleae alliance [57], which, according to the 92/43/EEC Directive, refers to the habitat of European interest "Molinia meadows on calcareous, peaty or clayey-silt-laden soils (Molinion caeruleae)" (code 6410). Mainly due to its wide 
distribution, O. vulgatum has been assessed as LC at European level [58], nevertheless, currently ferns and lycophytes have to face a new kind of risk related to ongoing climate change and human-related environmental disturbances such as eutrophication, pollution, habitat loss, alteration of hydrological regimes, and overexploitation [59-62]. Few data were available on the distribution of this small fern, and the conservation status at regional level (Italian and/or Sardinian) was not yet assessed.

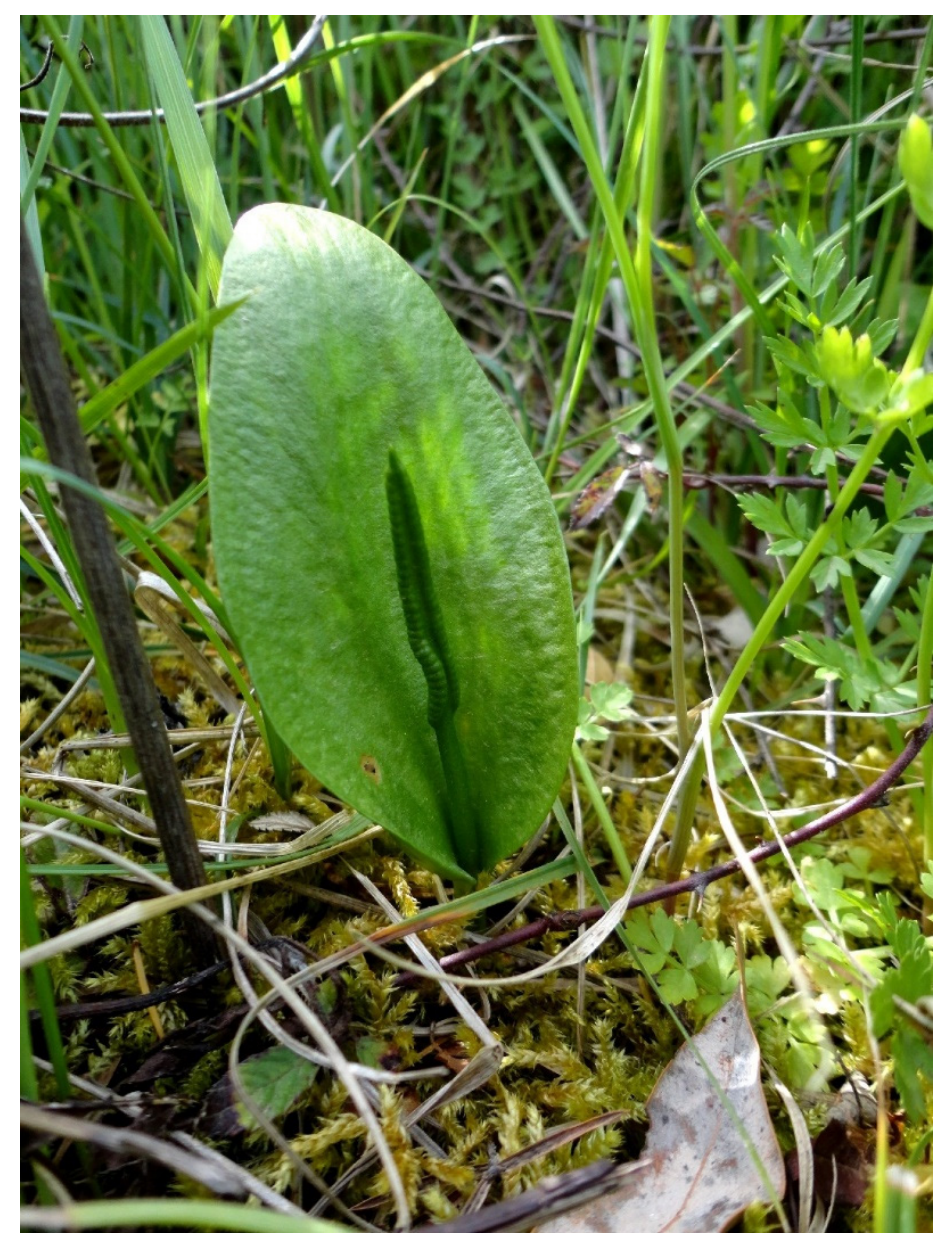

Figure 5. Ophioglossum vulgatum L. detail (photo by Giuseppe Fenu).

Data on the geographical distribution, ecology, and status of $O$. vulgatum populations in Sardinia were collected by both bibliographic, herbarium specimens or database records and fieldwork carried out during the last ten years. Specifically, field surveys were focused on the localities for which herbarium specimens and other bibliographic data were available, and in other areas ecologically suitable where this species could potentially occur. When a locality was confirmed or discovered, the following analyses were undertaken. The geographical limits of localities were mapped each year and areas visually estimated to detect any annual changes in area occupied. For each locality, we noted the altitudinal range, slope, aspect, and habitat type.

Population size was determined by a direct count of the total number of plants, distinguishing the juvenile from the mature individuals. Among all the confirmed populations, as part of the monitoring and conservation activities carried out on the Sardinian flora of conservation interest, two representative populations were selected based on ease and feasibility to be monitored over time: one on land managed by a public administration (Funtanamela), and one on a private land (Gedili). Following the same protocol developed and tested for other small plants in Sardinia [63,64], in each population, all plants were monthly monitored from April to August over an 8-year period. During each monitoring 
activity, all plants were counted, marked, and the reproductive status was assessed; all new seedlings that appeared inside the plots were also counted, measured, and mapped.

Author Contributions: Conceptualization, G.F., D.C. and G.B.; methodology, G.F. and D.C.; fieldwork, D.C., G.F., C.D., A.D., C.G., M.P. and G.B.; formal analysis, G.F. and D.C.; data curation, G.F. and D.C.; writing—original draft preparation, G.F. and D.C.; writing—review and editing, D.C., G.F., C.D., A.D., C.G., M.P. and G.B.; All authors have read and agreed to the published version of the manuscript.

Funding: This research received no external funding.

Data Availability Statement: Detailed data of monitoring are available upon request.

Acknowledgments: The Care-Mediflora project (http:/ / www.CARE-MEDIFLORA.eu/, accessed on 9 June 2021) is gratefully acknowledged for supporting the realization of the protective fence in Funtanamela.

Conflicts of Interest: The authors declare no conflict of interest.

\section{References}

1. Myers, N.; Mittermeier, R.A.; Mittermeier, C.G.; Fonseca, G.A.B.; Kent, J. Biodiversity hotspots for conservation priorities. Nature 2000, 403, 853-858. [CrossRef]

2. Médail, F. Plant Biogeography and Vegetation Patterns of the Mediterranean Islands. Bot. Rev. 2021. [CrossRef]

3. Cañadas, E.M.; Fenu, G.; Peñas, J.; Lorite, J.; Mattana, E.; Bacchetta, G. Hotspots within hotspots: Endemic plant richness, environmental drivers, and implications for conservation. Biol. Conserv. 2014, 170, 282-291. [CrossRef]

4. Nogué, S.; de Nascimento, L.; Froyd, C.A.; Wilmshurst, J.M.; de Boer, E.J.; Coffey, E.E.; Whittaker, R.J.; Fernández-Palacios, J.M.; Willis, K.J. Island biodiversity conservation needs paleoecology. Nat. Ecol. Evol. 2017, 1, 1-9. [CrossRef]

5. Weigelt, P.; Jetz, W.; Kreft, H. Bioclimatic and physical characterization of the world's islands. Proc. Natl. Acad. Sci. USA 2013, 110, 15307-15312. [CrossRef] [PubMed]

6. Médail, F. The specific vulnerability of plant biodiversity and vegetation on Mediterranean islands in the face of global change. Reg. Environ. Chang. 2017, 17, 1775-1790. [CrossRef]

7. Kueffer, C.; Daehler, C.C.; Torres-Santana, C.W.; Lavergne, C.; Meyer, J.Y.; Otto, R.; Silva, L. A global comparison of plant invasions on oceanic islands. Perspect. Plant Ecol. 2010, 12, 145-161. [CrossRef]

8. van Kleunen, M.; Dawson, W.; Essl, F.; Pergl, J.; Winter, M.; Weber, E.; Kreft, H.; Weigelt, P.; Kartesz, J.; Nishino, M.; et al. Global exchange and accumulation of non-native plants. Nature 2015, 525, 100-103. [CrossRef] [PubMed]

9. Caujapé-Castells, J.; Tye, A.; Crawford, D.J.; Santos-Guerra, A.; Sakai, A.; Beaver, K.; Lobin, W.; Vincent, F.F.B.; Moura, M.; Jardim, R.; et al. Conservation of oceanic island floras: Present and future global challenges. Perspect. Plant Ecol. Evol. Syst. 2010, 12, 107-130. [CrossRef]

10. Vogiatzakis, I.N.; Mannion, A.M.; Sarris, D. Mediterranean island biodiversity and climate change: The last 10,000 years and the future. Biodivers. Conserv. 2016, 25, 2597-2627. [CrossRef]

11. Cramer, W.; Guiot, J.; Fader, M.; Garrabou, J.; Gattuso, J.P.; Iglesias, A.; Lange, M.A.; Lionello, P.; Llasat, M.C.; Paz, S.; et al. Climate change and interconnected risks to sustainable development in the Mediterranean. Nat. Clim. Chang. 2018, 8, 972-980. [CrossRef]

12. Lewis, S.L.; Maslin, M.A. Defining the Anthropocene. Nature 2015, 519, 171-180. [CrossRef]

13. Ceballos, G.; Ehrlich, P.R.; Barnosky, A.D.; García, A.; Pringle, R.M.; Palmer, T.M. Accelerated modern human-induced species losses: Entering the sixth mass extinction. Sci. Adv. 2015, 1, e1400253. [CrossRef]

14. Pollock, L.J.; O'Connor, L.M.; Mokany, K.; Rosauer, D.F.; Talluto, M.V.; Thuiller, W. Protecting Biodiversity (in all its complexity): New models and methods. Trends Ecol. Evol. 2020, 35, 1119-1128. [CrossRef] [PubMed]

15. Gray, A. The ecology of plant extinction: Rates, traits and island comparisons. Oryx 2018, 53, 424-428. [CrossRef]

16. Fois, M.; Bacchetta, G.; Cuena-Lombrana, A.; Cogoni, D.; Pinna, M.S.; Sulis, E.; Fenu, G. Using extinctions in species distribution models to evaluate and predict threats: A contribution to plant conservation planning on the island of Sardinia. Environ. Conserv. 2018, 45, 11-19. [CrossRef]

17. Leclerc, C.; Courchamp, F.; Bellard, C. Insular threat associations within taxa worldwide. Sci. Rep. 2018, 8, 6393. [CrossRef]

18. Boehm, M.M.A.; Cronk, Q.C.B. Dark extinction: The problem of unknown historical extinctions. Biol. Lett. 2021, 17, 20210007. [CrossRef]

19. Thompson, J.D. Plant Evolution in the Mediterranean: Insights for Conservation, 2nd ed.; Oxford University Press: Oxford, UK, 2020; p. 464.

20. López-Alvarado, J.; Mameli, G.; Farris, E.; Susanna, A.; Filigheddu, R.; Garcia-Jacas, N. Islands as a crossroad of evolutionary lineages: A case study of Centaurea sect. Centaurea (Compositae) from Sardinia (Mediterranean Basin). PLoS ONE 2020, 15, e0228776. 
21. Fenu, G.; Bacchetta, G.; Christodoulou, C.S.; Cogoni, D.; Fournaraki, C.; Giusso del Galdo, G.P.; Gotsiou, P.; Kyratzis, A.; Piazza, C.; Vicens, M.; et al. A Common approach to the conservation of threatened island vascular plants: First results in the Mediterranean Basin. Diversity 2020, 12, 157. [CrossRef]

22. Bartolucci, F.; Peruzzi, L.; Galasso, G.; Albano, A.; Alessandrini, A.; Ardenghi, N.M.G.; Astuti, G.; Bacchetta, G.; Ballelli, S.; Banfi, E.; et al. An updated checklist of the vascular flora native to Italy. Plant Biosyst. 2018, 152, 179-303. [CrossRef]

23. Fenu, G.; Fois, M.; Cañadas, E.M.; Bacchetta, G. Using endemic-plant distribution, geology and geomorphology in biogeography: The case of Sardinia (Mediterranean Basin). Syst. Biodivers. 2014, 12, 181-193. [CrossRef]

24. Balmford, A.; Bennun, L.; Ten Brink, B.; Cooper, D.; Côté, I.M.; Crane, P.; Dobson, A.; Dudley, N.; Dutton, I.; Green, R.E.; et al. The convention on biological diversity's 2010 target. Science 2005, 307, 212-213. [CrossRef]

25. Fenu, G.; Bacchetta, G.; Giacanelli, V.; Gargano, D.; Montagnani, C.; Orsenigo, S.; Cogoni, D.; Rossi, G.; Conti, F.; Santangelo, A.; et al. Conserving plant diversity in Europe: Outcomes, criticisms and perspectives of the habitats directive application in Italy. Biodivers. Conserv. 2017, 26, 309-328. [CrossRef]

26. Moreno-Saiz, J.C.; Albertos, B.; Ruiz-Molero, E.; Mateo, R.G. The European Union can afford greater ambition in the conservation of its threatened plants. Biol. Conserv. 2021, 261, 109231. [CrossRef]

27. Fenu, G.; Cogoni, D.; Pinna, M.S.; Bacchetta, G. Threatened Sardinian vascular flora: A synthesis of 10 years of monitoring activities. Plant Biosyst. 2015, 149, 473-482. [CrossRef]

28. Ma, Y.; Chen, G.; Grumbine, R.E.; Dao, Z.; Sun, W.; Guo, H. Conserving plant species with extremely small populations (PSESP) in China. Biodivers. Conserv. 2013, 22, 803-809. [CrossRef]

29. Bacchetta, G.; Fenu, G.; Mattana, E. A checklist of the exclusive vascular flora of Sardinia with priority rankings for conservation. An. Jardin Bot. Madrid. 2012, 69, 81-89. [CrossRef]

30. Gauthier, P.; Debussche, M.; Thompson, J.D. Regional priority setting for rare species based on a method combining three criteria. Biol. Conserv. 2010, 143, 1501-1509. [CrossRef]

31. Schatz, B.; Gauthier, P.; Debussche, M.; Thompson, J.D. A decision tool for listing species for protection on different geographic scales and administrative levels. J. Nat. Conserv. 2014, 22, 75-83. [CrossRef]

32. Schmeller, D.S.; Gruber, B.; Budrys, E.; Framsted, E.; Lengyel, S.; Henle, K. National responsibilities in European species conservation: A methodological review. Conserv. Biol. 2008, 22, 593-601. [CrossRef]

33. Sulis, E.; Bacchetta, G.; Cogoni, D.; Fenu, G. From global to local scale: Where is the best for conservation purpose? Biodivers. Conserv. 2021, 30, 183-200. [CrossRef]

34. Ren, H.; Zhang, Q.; Lu, H.; Liu, H.; Guo, Q.; Wang, J.; Jian, S. Wild plant species with extremely small populations require conservation and reintroduction in China. Ambio 2012, 41, 913-917. [CrossRef] [PubMed]

35. Yang, J.; Cai, L.; Liu, D.; Chen, G.; Gratzfeld, J.; Sun, W. China's conservation program on plant species with extremely small populations (PSESP): Progress and perspectives. Biol. Conserv. 2020, 244, 108535. [CrossRef]

36. Chiappini, M.; Scrugli, A. Nuovo reperto di Ophioglossum vulgatum L. (Ophioglossaceae) in Sardegna. Atti Soc. Tosc. Sc. Nat. Mem. Ser. B 1982, 89, 207-212.

37. Iiriti, G. Flora e Paesaggio Vegetale del Sarrabus-Gerrei (Sardegna Sud Orientale). Ph.D. Thesis, University of Cagliari, Cagliari, Italy, 2006.

38. Cogoni, D.; Sulis, E.; Bacchetta, G.; Fenu, G. The unpredictable fate of the single population of a threatened narrow endemic Mediterranean plant. Biodiv. Conserv. 2019, 28, 1799-1813. [CrossRef]

39. Westerband, A.C.; Funk, J.L.; Barton, K.E. Review: Intraspecific trait variation in plants: A renewed focus on its role in ecological processes. Ann. Bot. 2021, 127, 397-410. [CrossRef]

40. Welander, K. Spatial and temporal dynamics of wild boar (Sus scrofa) rooting in a mosaic landscape. J. Zool. 2000, 252, 263-271. [CrossRef]

41. Burrascano, S.; Giarrizzo, E.; Bonacquisti, S.; Copiz, R.; Del Vico, E.; Fagiani, S.; Mortelliti, A.; Blasi, C. Quantifying Sus scrofa rooting effects on the understorey of the deciduous broadleaf forests in Castelporziano Estate. Rendiconti Lincei 2015, 26, 317-324. (In Italian) [CrossRef]

42. Bongi, P.; Tomaselli, M.; Petraglia, A.; Tintori, D.; Carbognani, M. Wild boar impact on forest regeneration in the northern Apennines. Forest Ecol. Manag. 2017, 391, 230-238. (In Italian) [CrossRef]

43. Perrino, E.V.; Musarella, C.M.; Magazzini, P. Management of grazing Italian river buffalo to preserve habitats defined by Directive 92/43/EEC in a protected wetland area on the Mediterranean coast: Palude Frattarolo, Apulia, Italy. Euro-Mediterr. J Environ. Integr. 2021, 6, 32. [CrossRef]

44. Barasona, J.A.; Carpio, A.; Boadella, M.; Gortazar, C.; Pineiro, X.; Zumalacárregui, C.; Vicente, L.; Viñuela, J. Expansion of native wild boar populations is a new threat for semi-arid wetland areas. Ecol. Indic. 2021, 125, 107563. [CrossRef]

45. Fenu, G.; Bacchetta, G.; Charalambos, S.C.; Fournaraki, C.; del Galdo, G.P.G.; Gotsiou, P.; Kyratzis, A.; Piazza, C.; Vicens, M.; Pinna, M.P.; et al. An early evaluation of translocation actions for endangered plant species on Mediterranean islands. Plant Divers. 2019, 41, 94-104. [CrossRef]

46. Abeli, T.; Cauzzi, P.; Rossi, G.; Pistoja, F.; Mucciarelli, M. A gleam of hope for the critically endangered Isoëtes malinverniana: Use of small-scale translocations to guide conservation planning. Aquat. Conserv. 2018, 28, 501-505. [CrossRef]

47. Magrini, S.; Azzella, M.M.; Bolpagni, R.; Zucconi, L. In Vitro Propagation of Isoëtes sabatina (Isoetaceae): A Key Conservation Challenge for a Critically Endangered Quillwort. Plants 2020, 9, 887. [CrossRef] 
48. Godefroid, S.; Piazza, C.; Rossi, G.; Buord, S.; Stevens, A.D.; Aguraiuja, R.; Cowelli, C.; Weekley, C.W.; Vogg, G.; Iriondo, J.M.; et al. How successful are plant species reintroductions? Biol. Conserv. 2011, 144, 672-682. [CrossRef]

49. Ma, Y.; Sun, W. Rescuing conservation of plant species with extremely small populations (PSESP): Opportunities and challenges. Biodivers. Sci. 2015, 23, 430-432. [CrossRef]

50. Sun, W.; Han, C. Researches and conservation for plant species with extremely small populations (PSESP). Biodivers. Sci. 2015, 23, 426-429. [CrossRef]

51. Yang, W.; Xiang, Z.; Zhang, S.; Kang, H.; Shi, F. Plant species with extremely small populations (PSESP) and their significance in China's national plant conservation strategy. Biodivers. Sci. 2015, 23, 419-425. [CrossRef]

52. Sun, W.B.; Ma, Y.P.; Blackmore, S. How a new conservation action concept has accelerated plant conservation in China. Trends Plant Sci. 2019, 24, 4-6. [CrossRef]

53. Volis, S. How to conserve threatened Chinese plant species with extremely small populations? Plant Divers. 2016, 38, 45-52. [CrossRef]

54. Crane, P. Conserving our global botanical heritage: The PSESP plant conservation program. Plant Divers. 2020, 42, 319. [CrossRef] [PubMed]

55. Ferrarini, E.; Ciampolini, F.; Sermolli, R.E.G.P.; Marchetti, D. Iconographia Palynologica Pteridophytorum Italiae. Webbia 1986, 40, 1-201. [CrossRef]

56. Marchetti, D. Le pteridofite d'Italia. Ann. Mus. Civ. Rovereto 2004, 19, 71-231.

57. Muller, S. Assessing occurrence and habitat of Ophioglossum vulgatum L. and other Ophioglossaceae in European forests. Significance for nature conservation. Biodiver. Conserv. 2000, 9, 673-681. [CrossRef]

58. García Criado, M.; Väre, H.; Nieto, A.; Elias, R.B.; Dyer, R.; Ivanenko, Y.; Ivanova, D.; Lansdown, R.; Molina, J.A.; Rouhan, G.; et al. European Red List of Lycopods and Ferns; IUCN: Brussels, Belgium, 2017; 59p.

59. Pimm, S.L.; Raven, P. Extinction by numbers. Nature 2000, 403, 843-845. [CrossRef]

60. Wani, I.A.; Kumar, V.; Verma, S.; Jan, A.T.; Rather, I.A. Dactylorhiza hatagirea (D. Don) Soo: A Critically Endangered Perennial Orchid from the North-West Himalayas. Plants 2020, 9, 1644. [CrossRef]

61. Castanho, R.A.; Gómez, J.M.N.; Couto, G.; Pimentel, P.; Sousa, Á.; Batista, M.d.G. Analyzing the Patterns, Trends and Dynamics of the Land-Use Changes in Azores Region: From 1990 to 2018. Sustainability 2021, 13, 5433. [CrossRef]

62. Raposo, M.A.M.; Gomes, C.J.P.; Nunes, L.J.R. Selective Shrub Management to Preserve Mediterranean Forests and Reduce the Risk of Fire: The Case of Mainland Portugal. Fire 2020, 3, 65. [CrossRef]

63. Fenu, G.; Cogoni, D.; Ulian, T.; Bacchetta, G. The impact of human trampling on a threatened coastal Mediterranean plant: The case of Anchusa littorea Moris (Boraginaceae). Flora 2013, 208, 104-110. [CrossRef]

64. Cogoni, D.; Fenu, G.; Bacchetta, G. Effects of timing of emergence and microhabitat conditions on the seedling performance of a coastal Mediterranean plant. Ecoscience 2013, 20, 131-136. [CrossRef] 